\title{
Functional Analysis on Bali Botanical Garden for Society
}

\author{
Taufik Akbar \\ Indonesia Institute of Sciences, Tabanan, Indonesia \\ Email:t4uflk.kr@gmail.com
}

\begin{abstract}
Bali Botanical Gardens as one of the government agencies that play a role in conservation, research, education, tourism, and environmental services, have a great responsibility for the conservation of biodiversity in Indonesia. Bali Botanical Gardens take website advantage of existing services to promote the service program in the field of conservation and environmental education as well as contributing to socialize about preserving the environment. Bali botanical gardens provide a variety of information with the submission that is easily understood by tourists who want to visit. Bali Botanical Gardens itself makes the website and facebook fan page as the promotion, reporting and socialise both in terms of reporting to support e-government and the most important is the focus in the field of environment, the conservation of nature, the introduction and utilization of research results and an introduction to the various types of Mountain crops to the public. In addition to the website and facebook fan page, Bali Botanical Gardens also use TripAdvisor know the feedback from the community after a visit to the Bali Botanical Gardens.
\end{abstract}

Keywords---Bali botanical garden, environmental education, internet, website.

\section{Introduction}

\section{Issue Background}

Indonesia's tourism has great potential and still need to be developed, along with the development of civil society. Tourism has become a trend and lifestyle in the midst of today's modern society. In addition to increased social and economic activity in the community has been oriented information. information technology has become an integral part again in daily life - today, ranging from trade / business (e-commerce / e-business), education (tele-education), health (telemedicine), government (e-Government), transport, industry, tourism, the environment for the entertainment sector (Astiari et al., 2018).

With internet access, information on tourism can be easily communicated to travelers. Media information famous sites on the Internet. Through the website, we can get to know various things about the holidays. Some of the technologies of the techniques and methods of collecting information (collect), storage (storage), processing and production to the transmission of information from and to the industry or the public effectively and quickly. It is necessary for the preparation and deep thinking about ways to promote the attraction that is becoming more recognized by domestic and foreign travelers (Kapoor, 2016).

\section{Problem Formulation}

Cultural diversity and natural beauty is a potential in the tourism sector require thought and strategy for the development, marketing, and preservation in the world of tourism. In order to understand the thinking and development, we need to find solutions to the problems that already exist in each place of tourist attraction. 


\section{Discussion}

\section{Tourism Information System}

Tourism Information System is a system that provides information-information about the appeal, the area attractions or rides - rides in a draw object/area. The system is also present on some of the information that supports tourism activities such as accommodation, transportation, tickets and hotel (Suriani, 2018).

Utilization of information technology in the field of tourism is done by entering data about attractions, hotels, and inns around the tourist sites. Other functions for accessing weather information and event location nearby often held, the uniqueness of the local culture and traditions of the area of the tourist area. As well as a map of the spread of tourism attractions with directions on routes of travel and transportation use. Utilization of Information Technology for Development of Tourism of the role of government, private and community because of these 3 factors that determine the benefits of tourism services (Omer, 2017).

In this case, information technology is only one small component in company format. Other components are the processes and procedures, organizational structure, human resources, products, customers, suppliers, partners, and others. In theory, at one extreme, a good information system does not always have to have the information technology components (see company with a turnover of billions of small producers); while at the other extreme, the computer very important role in the creation of products (note the Japanese manufacturing companies that employ robots for the entire assembly process). So that the reliability of information systems within the enterprise or organization lies in the relationship between the components - components that exist, so it can be manufactured and supplied useful information (accurate, reliable, detailed, fast, relevant, etc.) to the institution concerned.

Information technology and Promotions are now increasingly flourishing, Information technology today is growing so rapidly along with the emergence of various types of smartphones, so boost the promotion of services and products from companies or agencies both public and private, have started reducing the sale by using the manual method such as brochures, newspapers, television, radio, or rely on the dissemination of information through door to door. With the internet facility that is so easily available and accessible, promotion now can use the internet in the form of media companies or government agency website. The Internet can cover all aspects of presents so much information needed by users (Parraga et al., 2017).

With the convenience obtained from the internet media, websites can also be said to be the second office to represent its role as a media campaign aimed at improving services to facilitate the dissemination of information on the introduction of products or services over the Internet can be accessed in real time by Internet users, In addition to being a media promotion, the website also serves as the identity of a company or government agency can provide reporting and data storage either as a source or reference literature online is commonly referred to as a transparent online catalog on the other hand has a role as a media publication.

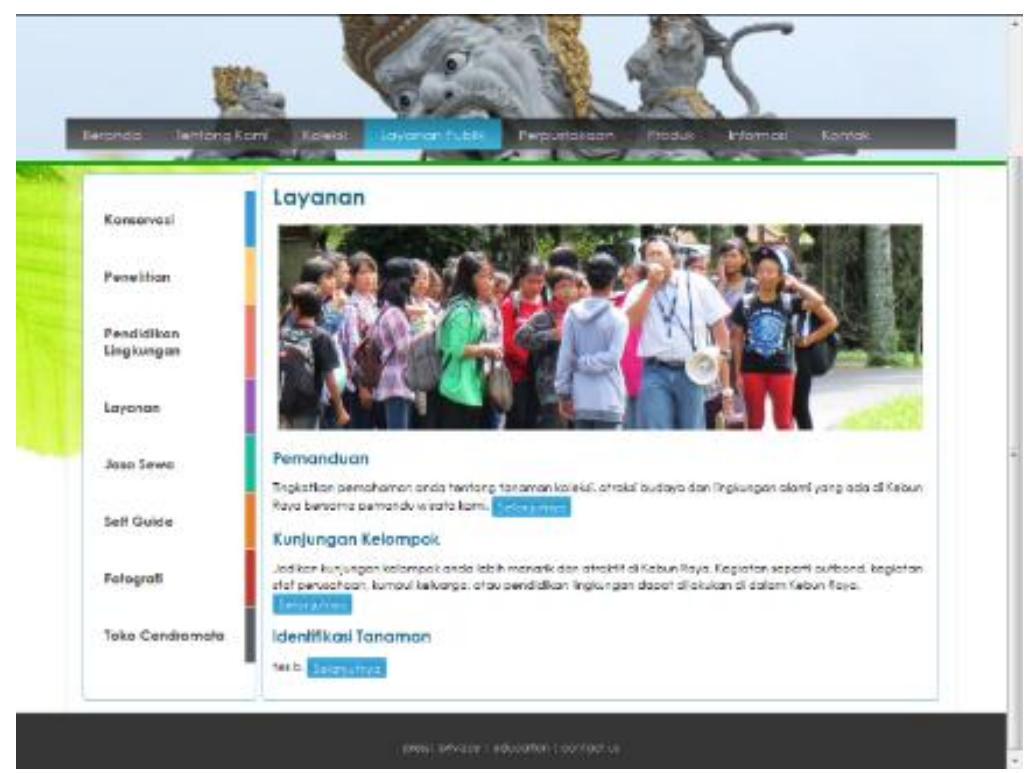

Figure 1. Website Bali Botanical Gardens 
Bali botanical garden itself as one government agencies that play a role in conservation, research, education, tourism, and environmental services, have a great responsibility towards the preservation of biodiversity and maintaining plants in Indonesia. Therefore Bali Botanical Gardens through media website presents the program - service program in the field of conservation and environmental education and contribute to environmental conservation campaign.

Educational programs offered through this website is packed with varied scenery that can be precisely targeted delivery in the areas of biodiversity, which is referenced in the information presentation/packaging on the website (Singh, 2016). This is to encourage visits to its own website online is increasing every year. Bali Botanical Gardens has service environmental education, with participants from the student to the general public can participate. The materials also vary, depending on the participants who took part. In this environment education activities are divided from basic materials, intermediate, and expert.

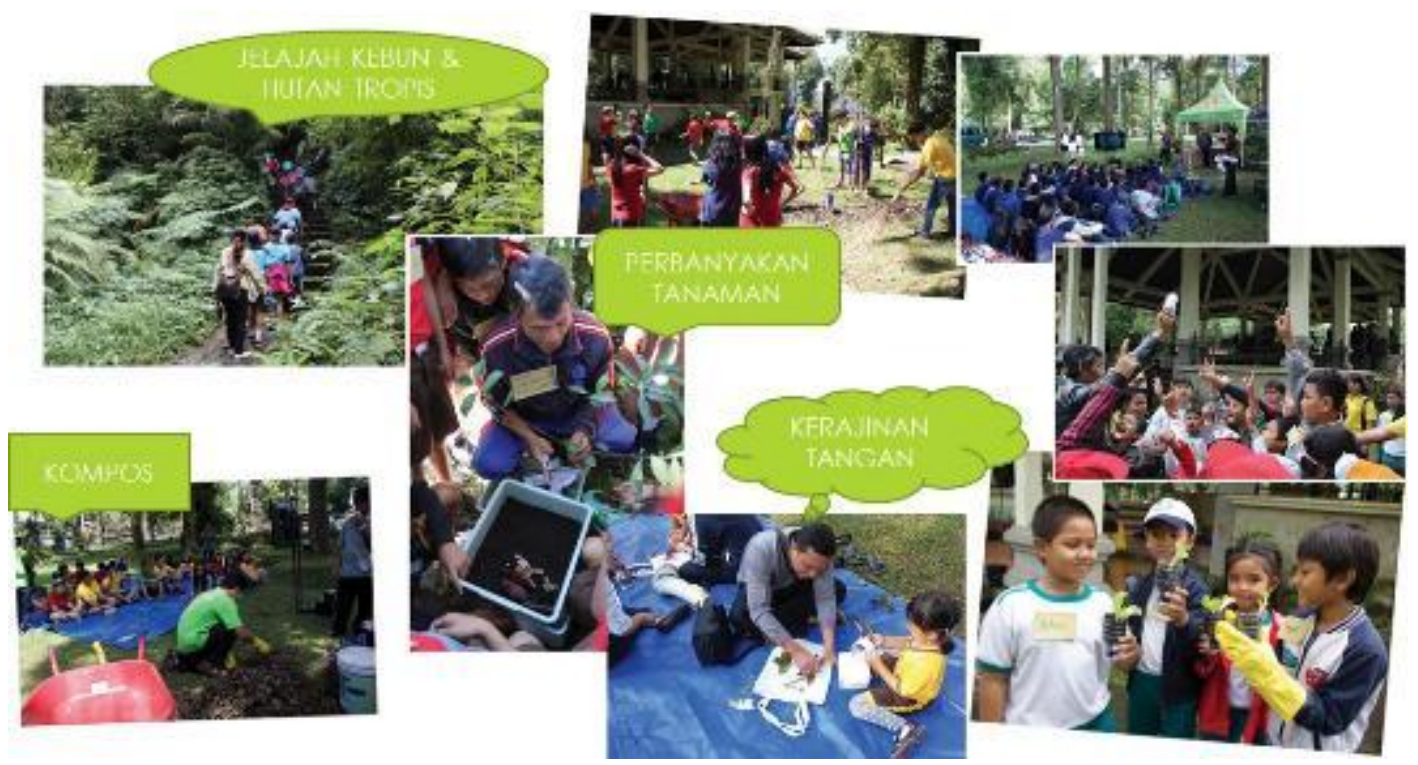

Figure 2. Environmental education activity

The basic ingredients are awarded to participants who are in school in Early Childhood Education (ECD), kindergarten (kindergarten) and elementary school (SD). Intermediate materials provided to participants who are in junior high school (SMP) and senior high school (SMA). While the material is given to participants of student experts and the general public. Each material will be explained as follows:

1. Participants from kindergarten and primary school will be given materials on:

a) Introduction to basic crops such as what stems, roots and leaves.

b) Teach for planting.

c) Making crafts from scrap materials.

d) Interactive games.

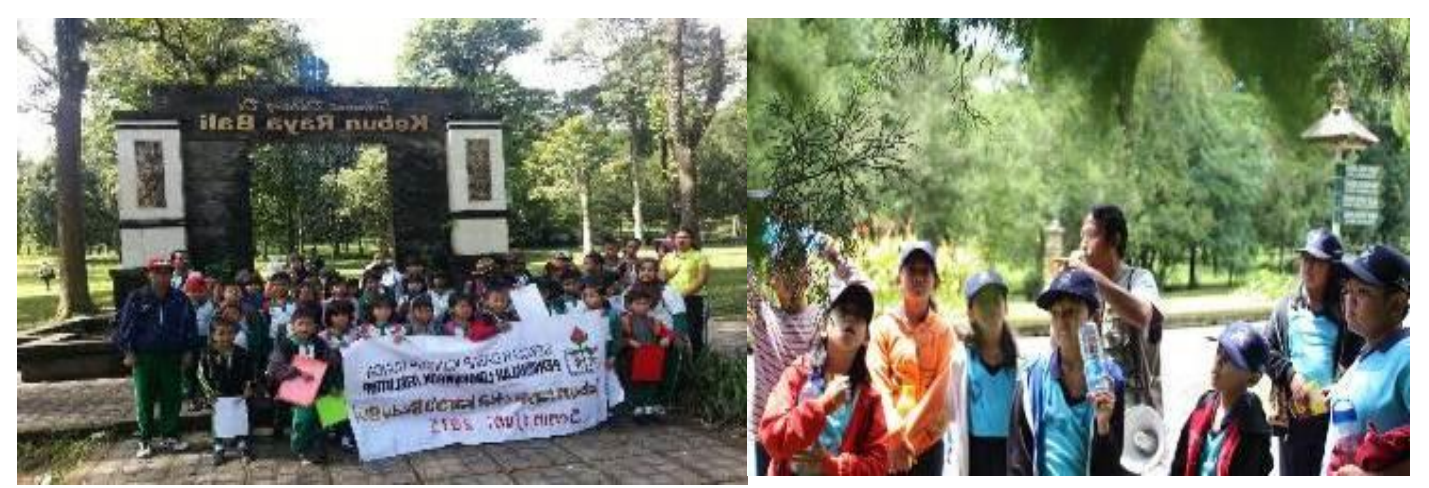

Figure 3. Participants kindergarten / early childhood and elementary school 
2. Members of the middle and high school will be given materials on:

a) Free introduction to the plant.

b) Teach how to make compost from nature.

c) Teach how to propagate plants.
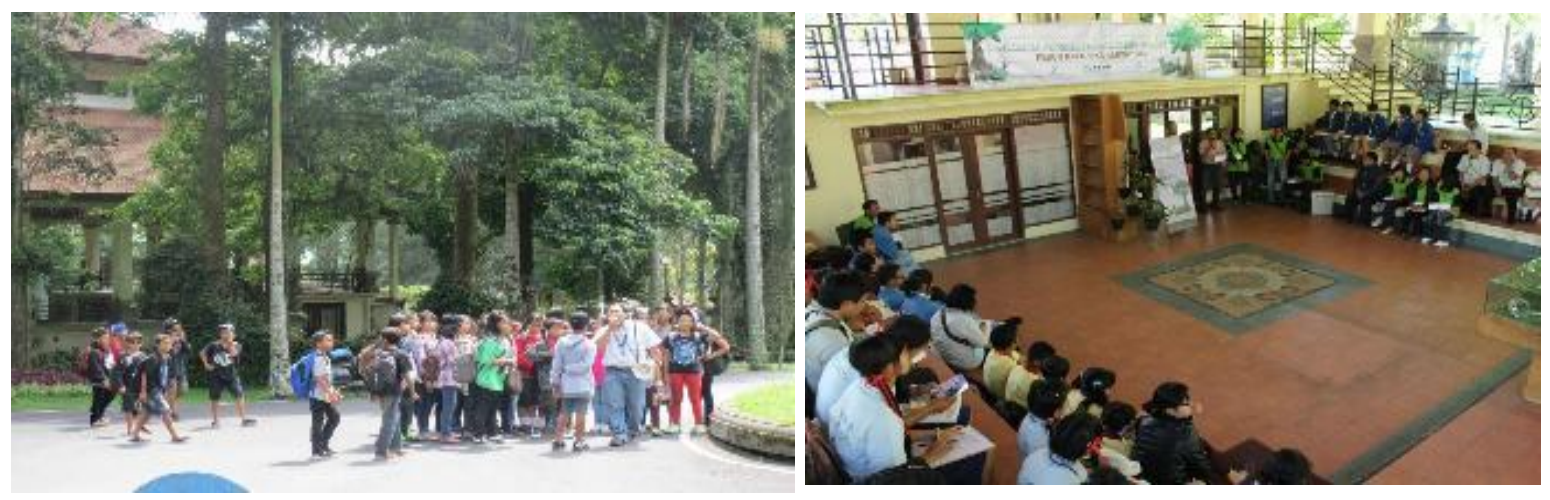

Figure 3. School participants intermediate level

3. Participants of the student and the general public will be given materials on:

a) Free introduction to the plant.

b) Invited to view the tissue culture lab.

c) Teach how to make compost from nature.
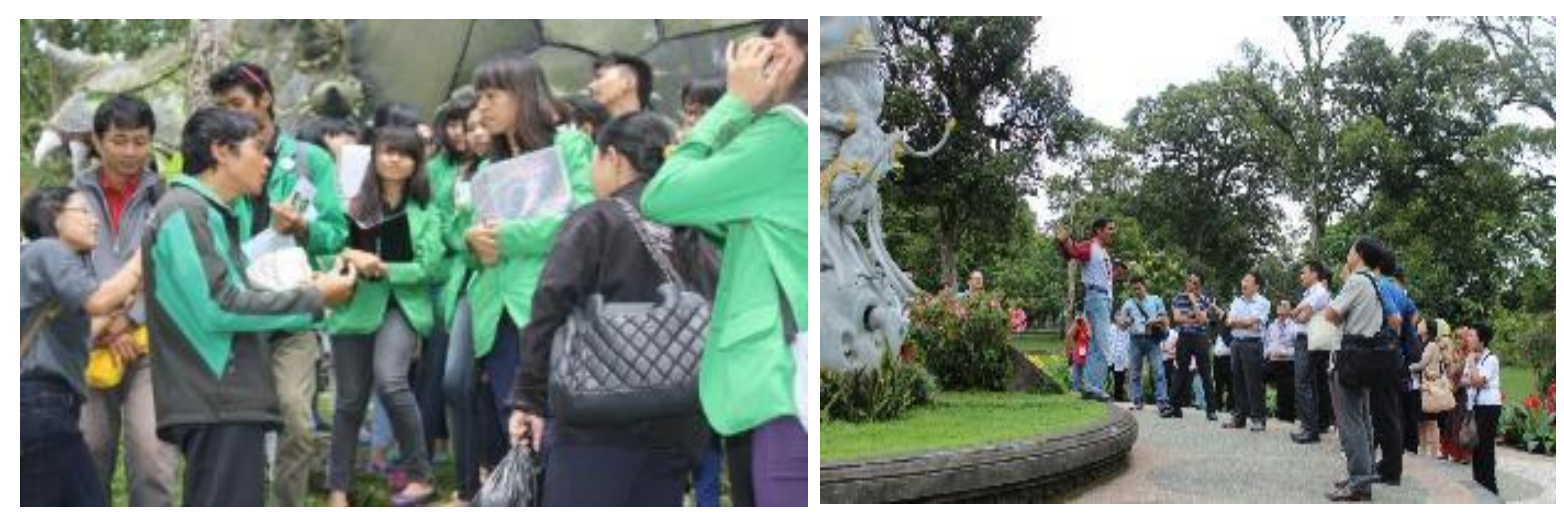

Figure 4. Student participants and the public

\section{Conclusions}

The conclusions of this article are as follows:

1) Through the website, we can find various kinds of information that needed no exception regarding tourism.

2) Bali Botanical Gardens website and take advantage of existing services to promote the service program in the field of conservation and environmental education as well as contributing to socialize about preserving the environment.

3) Bali botanical garden itself makes the website and facebook fan page as the proposition promotion, reporting, and socialization.

4) Bali botanical gardens have environmental education services, with participants from the students to the general public could participate.

5) With varied environmental education, activities are expected to deliver information in the field of a biological target. 
Recommendations

The suggestion of this article is as follows:

1) There are many other attractions that do not have a website so that often the information only to the environment of the surrounding area only.

2) The importance of the involvement of the government and society to always support any activity related to tourism.

Educational programs especially for children, so that when he visited the attraction they can travel while learning.

\section{References}

Astiari, N. K. A., Kartini, L., Sulistiawati, N. P. A., \& Rai, I. N. (2018). Efforts to produce Siamese citrus fruit out of season and fruit quality improvement through application of potassium nitrate and agrodyke fertilizer. International Journal of Life Sciences, 2(3), 48-58. https://doi.org/10.29332/ijls.v2n3.206

Kapoor, K. (2016). Transformation of Eliza from a flower girl to duchess. International research journal of engineering, IT \& scientific research, 2(7), 62-67.

Omer, A. M. (2017). Identifying, developing, and moving sustainable communities through application of bioenergy for energy or materials: future perspective through energy efficiency. International Journal of Life Sciences, 1(1), 9-39. https://doi.org/10.21744/ijls.v1i1.9

Parraga, W. E. R., Parraga, M. A. C., Salazar, M. J. V., \& Albear, J. J. H. (2017). Reusing the coconut clay (brick) as construction material. International research journal of engineering, IT \& scientific research, 3(4), 102-109.

Singh, D. (2016). Study of ethno-botanical flora of dakingari, kebbi state Nigeria, west tropical Africa. International research journal of engineering, IT \& scientific research, 2(5), 17-28.

Suriani, N. L. (2018). Bioactive substance use of leaf extract of piper caninum blume pressing for blas disease and increase production in rice. International Journal of Life Sciences, 2(2), 42-50. https://doi.org/10.29332/ijls.v2n2.156 